\title{
Virus Coinfection is a Predictor of Radiologically Confirmed Pneumonia in Children with Bordetella pertussis Infection
}

\author{
Wujun Jiang $\cdot$ Min Wu $\cdot$ Sainan Chen · Anrong Li $\cdot$ Kun Wang \\ Yuqing Wang · Zhengrong Chen · Chuangli Hao · Xuejun Shao • \\ Jun $\mathrm{Xu}$
}

Received: October 12, 2020 / Accepted: November 19, 2020 / Published online: December 3, 2020

(c) The Author(s) 2020

\section{ABSTRACT}

Introduction: This study aimed to prospectively investigate the burden of pertussis in southeast Chinese children hospitalized with lower respiratory tract infection (LRTI) during a pertussis outbreak and to compare the outcomes of Bordetella pertussis infection with or without virus coinfections.

Methods: Children $<24$ months of age hospitalized with LRTI were prospectively enrolled from January 2017 to December 2019. Demographic and clinical information were recorded, and respiratory tract samples were tested for the presence of $B$. pertussis and ten common viruses by polymerase chain reaction (PCR).

Electronic supplementary material The online version of this article (https://doi.org/10.1007/s40121020-00376-5) contains supplementary material, which is available to authorized users.

W. Jiang $\cdot$ M. Wu $\cdot$ S. Chen $\cdot$ A. Li $\cdot$ K. Wang ·

Y. Wang $(\bowtie) \cdot$ Z. Chen $\cdot$ C. Hao

Department of Respiratory Medicine, Children's

Hospital of Soochow University, Suzhou, China

e-mail: wang_yu_qing@126.com

W. Jiang

Department of Medicine, Children's Hospital of

Wujiang District, Suzhou, China

X. Shao J. Xu

Department of Clinical Laboratory, Children's

Hospital of Soochow University, Suzhou, China
Results: Bordetella pertussis PCR was positive in $6.1 \%(202 / 4287)$ of the patients. Only 146 (72.3\%) B. pertussis infections met the Centers for Disease Control and Prevention case definition for pertussis. Among the 202 subjects with B. pertussis infections, $81(40.1 \%)$ were coinfected with at least 1 respiratory virus, with human rhinovirus being the most commonly detected virus $(25.7 \%)$. No differences in clinical severity were observed between children with single $B$. pertussis infection and those with virus coinfection [odds ratio (OR) 0.75 ; 95\% confidence interval (CI) 0.39-1.44]. However, children with virus coinfection were significantly more likely to present with radiologically confirmed pneumonia than those with a single B. pertussis infection (OR 2.62; CI 1.39-4.91).

Conclusions: Bordetella pertussis infection contributed to a high proportion of LRTI hospitalizations among southeast Chinese children. There were no significant differences in clinical severity between children with virus coinfection and single $B$. pertussis infection, although children coinfected with virus coinfection presented with pneumonia more frequently than those with single $B$. pertussis infection.

Keywords: Clinical outcome; Coinfection; Pertussis; Virus 


\section{Key Summary Points}

\section{Why carry out this study?}

Bordetella pertussis infection results in significant morbidity and mortality in children and its re-emergence has been the focus of international attention.

However, due to limited laboratory routine pertussis testing, estimating the $B$. pertussis burden is challenging.

Does virus coinfection affect the disease severity of pertussis?

\section{What was learned from the study?}

Bordetella pertussis infection contributed to a high proportion of LRTI hospitalizations among southeast Chinese children.

There were no significant differences in clinical severity between children with virus coinfection and single $B$. pertussis infection, although children coinfected with virus coinfection presented with pneumonia more frequently than those with single $B$. pertussis infection.

\section{DIGITAL FEATURES}

This article is published with digital features, including a summary slide, to facilitate understanding of the article. To view digital features for this article go to https://doi.org/10.6084/ m9.figshare.13252535.

\section{INTRODUCTION}

Pertussis, caused by Bordetella pertussis (B. pertussis), results in significant morbidity and mortality in children. Outbreaks of pertussis have been reported over the past decades, and disease re-emergence has been the focus of international attention [1]. Liu et al. estimated that the percentage of under-5 childhood deaths due to pertussis was $0.9 \%$ in $2000-2015$ [2]. Yeung et al. also estimated that there were 24.1 million pertussis cases and 160,700 deaths from pertussis in children younger than 5 years in 2014 [3]. In China, the reported morbidity of pertussis declined from 100-200 per 100,000 persons before the 1970 s to less than 1 per 100,000 persons in 2012 (2517 in total) due to the introduction of vaccines in the 1970s [4]. However, the reported number of pertussis reached 3426 and 6373 cases in 2014 and 2015, respectively.

Due to limited laboratory infrastructure to support routine pertussis testing and underrecognition of pertussis among young infants, who may present with atypical symptoms, estimating the pertussis disease burden is challenging [5]. Most studies on the disease burden of pertussis selectively enrolled children with predefined symptoms, such as paroxysmal or prolonged cough, whereas infants might present with atypical symptoms according to previous observational studies $[6,7]$. There have been few studies on the incidence of pertussis in infants using broad inclusion criteria $[8,9]$. However, in China, the prevalence and clinical presentation of pertussis infection in children using broad inclusion criteria have never been thoroughly investigated.

Furthermore, as previous studies have reported, coinfection was quite common in $B$. pertussis infection. Frassanito et al. found that, in Italy, infants hospitalized for $B$. pertussis infection commonly have respiratory viral coinfections (47.2\%) [10]. A study from Beijing, northern China, revealed a high coinfection rate of $40.1 \%$ [11]. Our previous study also found a high coinfection detection rate of $59.4 \%$ [12]. To date, the relationship between the clinical severity and $B$. pertussis infection status with versus without respiratory viruses remains uncertain.

To address these issues, this study aimed to prospectively investigate the prevalence of pertussis in southeast Chinese children hospitalized with lower respiratory tract infection (LRTI) during an outbreak. Furthermore, we aimed to compare the clinical characteristics and the severity of illness in $B$. pertussis polymerase chain reaction (PCR)-positive children with 
respiratory virus coinfections to those with a single $B$. pertussis infection.

\section{METHODS}

\section{Study Population}

We conducted a prospective observational cohort study of consecutive children admitted to the Children's Hospital of Soochow University between January 2017 and December 2019. All patients admitted to the pulmonary department were screened for study eligibility daily. Patients aged 4 weeks to $<2$ years presenting with one or more symptoms suggestive of LRTI (defined as cough, increasing dyspnoea, sputum production, or fever) were eligible. Exclusion criteria included children rehospitalized within 7 days of discharge from a previous admission or those who had any underlying chronic comorbidities (congenital cardiorespiratory diseases or immunosuppressive/metabolic conditions).

\section{Study Setting}

The Children's Hospital of Soochow University is a tertiary referral hospital in southeast China, and has 1500 beds reserved for children $<15$ years old. The bed occupancy in 2018 was $100 \%$. Annual reports suggest that approximately 6000 children with acute respiratory infections are admitted to the respiratory department every year.

\section{Clinical Information}

Clinical characteristics of symptoms typically associated with $B$. pertussis, such as paroxysmal coughing, post-tussive vomiting, whoop, cyanosis, apnoea, and seizures, were collected for each study participant.

Chest radiographs were obtained on the day of admission and interpreted by radiologists. Radiologically confirmed pneumonia was defined as evidence of infiltrates or consolidation on chest X-ray [13]. Patients with severe $B$. pertussis infection were considered if they developed pneumonia requiring oxygen therapy, apnoea, seizures, or acute encephalopathy [14]. We evaluated demographic characteristics and risk factors for radiologically confirmed pneumonia and severe illness.

\section{Vaccination Status Determination}

Vaccination history was obtained by querying the "Suzhou Children's Vaccination Inquiry and Evaluation Platform" for dates, type, and manufacturer. This platform contains immunization data entered by healthcare providers in Suzhou. Vaccination status was determined according to the Chinese Center for Disease Control and Prevention recommendations for vaccination schedules. In 2010 , the diphtheria, tetanus, and acellular pertussis combined vaccine was recommended in China. It is administered as a primary series at 3,4 , and 5 months, followed by a booster dose at 24 months. Persons with no documented doses were classified as unvaccinated. Vaccination status was regarded as ever-vaccinated if $1-3$ doses were received.

\section{Microbiologic Assessment}

Nasopharyngeal aspirates were obtained from all patients within $24 \mathrm{~h}$ of admission. This involved passing a suction catheter through the nose with the intent of passing it into the lower part of the pharynx. The depth of penetration for the nasopharyngeal aspirate catheter was set at $7-9 \mathrm{~cm}$. A total of $2 \mathrm{ml}$ of nasopharyngeal aspirates was obtained and centrifuged at $500 \mathrm{~g}$ for $10 \mathrm{~min}$ and resuspended in $2 \mathrm{ml}$ of saline.

These specimens were tested for $B$. pertussis by a real-time (RT)-PCR assay at our centralized laboratory with previously methods described [15]. All RT-PCR assays were conducted alongside a $B$. pertussis-positive and -negative control to monitor the reliability of the assay. Oligonucleotide primers targeting IS481 and ptxS1 were used to amplify 145- and 191-bp products, respectively. All primers and probes were purchased from Sangon Biotech, Shanghai, China). The interpretation of the PCR algorithm is shown in Fig. 1. The PCR result was 


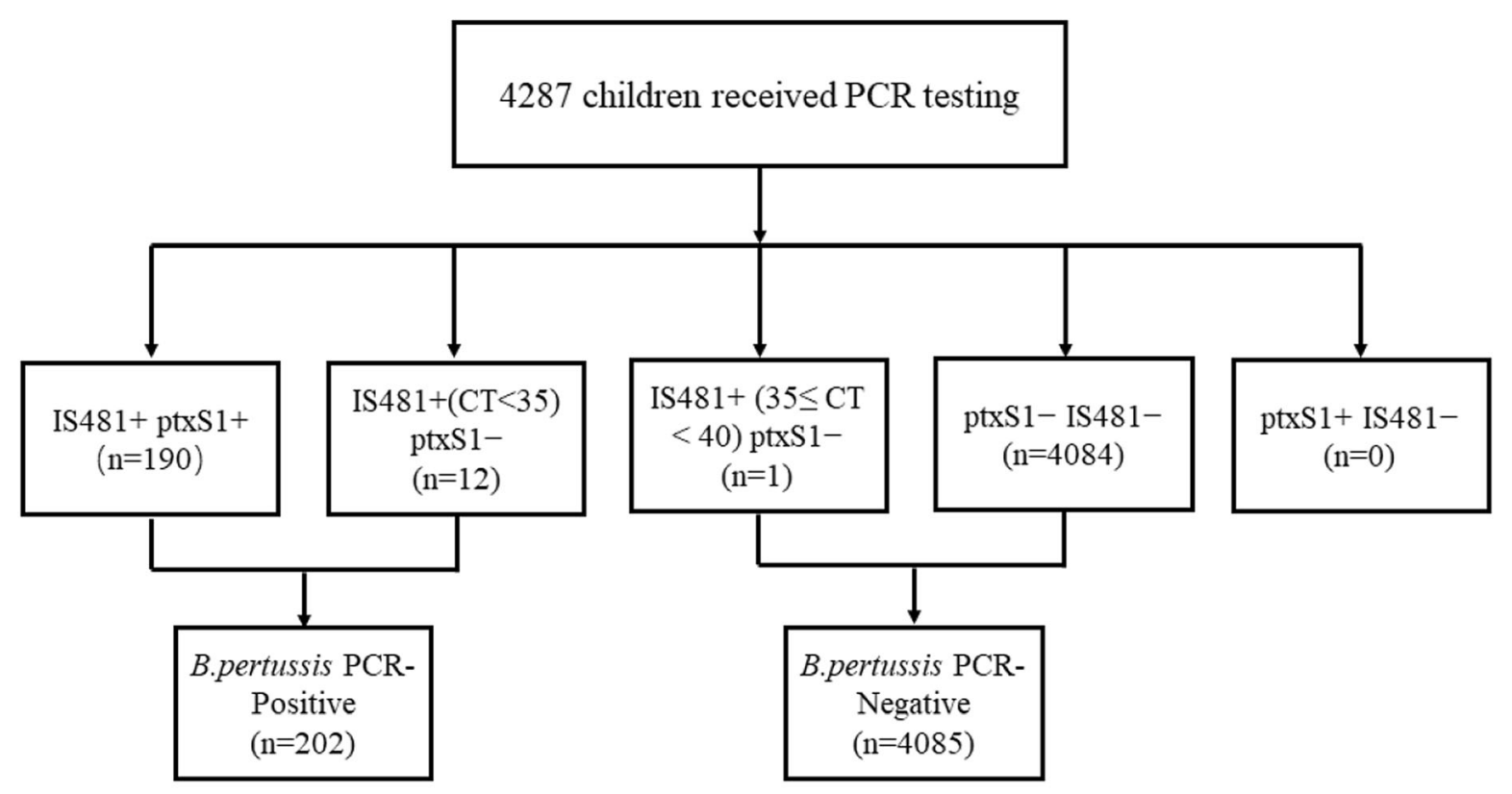

Fig. 1 Interpretation of real-time PCR algorithm

considered negative if the cycle threshold $\left(C_{\mathrm{T}}\right)$ $\geq 40$. Specimens that tested positive for both insertion sequence IS481 and pertussis toxin subunit S1 (ptxS1) were considered positive for $B$. pertussis. If a specimen was ptxS1 target-negative with an IS481 assay $C_{\mathrm{T}}<35$, it was also considered positive for $B$. pertussis.

Ten common viruses, including respiratory syncytial virus (RSV), human rhinovirus (HRV), human bocavirus (hBoV), influenza virus $A$, influenza virus $\mathrm{B}$, parainfluenza virus (PIV) I, PIV II, PIV III, adenovirus, and human metapneumovirus, were detected in nasopharyngeal aspirate specimens by real-time PCR, as previously described [16]. Viral RNA/DNA was extracted manually using a PCR purification kit (Sangon Biotech) according to the manufacturer's instructions. Our centralized laboratory followed the common International Standard Organization (ISO9001) framework and ISO15189 to maintain suitable quality assurance and quality control measures.

\section{Compliance with Ethics Guidelines}

The study protocol was approved by the Ethics Committee of the Children's Hospital of
Soochow University (No: 2016026) and was conducted in accordance with Good Clinical Practice guidelines and the Helsinki Declaration. Legal guardians of the study participants were counselled on the study and study-related procedures prior to obtaining a signed informed consent.

\section{Analysis}

We assessed our primary exposure (virus coinfection status), outcomes (radiologically confirmed pneumonia and severe illness), and potential confounders [including age, sex, vaccination status (unvaccinated vs. ever-vaccinated) and white blood cell (WBC) count] using univariate and bivariate statistics. To assess virus coinfection with respect to outcome, multiple logistic regressions were performed, including variables that were significant at the $P<0.2$ level in unadjusted analyses. Predictor variables significant at $P<0.05$ were retained in the final model, adjusted odds ratios were calculated, and model fit was assessed via the Hosmer-Lemeshow test. Data were analyzed by SPSS 22.0 (IBM, Armonk, NY, USA). 


\section{RESULTS}

\section{Epidemiological Features of $B$. pertussis}

Of 4779 eligible children with LTRI, 4287 $(89.7 \%)$ children were ultimately enrolled in the study (Fig. 2), of whom 2791 (65.1\%) were male. There were no differences in demographic characteristics between the enrolled and not enrolled children. The median age at admission was 4 months (IQR 2-9 months). Respiratory samples were collected from all the enrolled children for $B$. pertussis PCR testing. Of the 4287 children receiving $B$. pertussis PCR testing, 202 (6.1\%) tested positive. Of the 202 patients with B. pertussis infection, $109(54.0 \%)$ were males and 93 (46\%) were females. The male to female ratio was $1.17: 1$. The median age at admission was 3 months (IQR 2-6 months) (Table 1). Seasonal distribution of $B$. pertussis infection is shown in Fig. 3. Outbreaks began in summer months and peaked during July and August.

\section{Proportion of Viruses Detected}

Among the 202 subjects with B. pertussis-associated LTRI, $81(40.1 \%)$ were coinfected with at least 1 respiratory virus. HRV (25.7\%) and hBoV
$(8.4 \%)$ were the most commonly detected viruses. Nine patients $(4.5 \%)$ were coinfected with two viruses. The prevalence of identifying HRV was significantly higher among the $B$. pertussis PCR-positive children than among the PCR-negative children $(25.7 \%$ vs. $8.2 \%$, $P<0.01$ ), while RSV was less frequently detected in the $B$. pertussis PCR-positive children $(2.5 \%$ vs. $18.4 \%)$ (Table 2$)$.

\section{Clinical Presentation of the PCR-Positive Pertussis Children with or Without Virus Coinfection}

All cases with $B$. pertussis-associated infection had a history of cough at admission, but only 86 $(42.6 \%)$ had a cough duration $\geq 14$ days at admission. Paroxysmal cough was reported in $190(94.1 \%)$ of the cases with B. pertussis-associated infection, post-tussive emesis in 81 $(40.1 \%)$, wheezing in $58(28.7 \%)$, and whoop in $47(23.3 \%)$ cases. Fifty-six (29.7\%) did not meet the CDC criteria for probable pertussis. The mean WBC count was $17.7 \times 10^{9} / \mathrm{L}$. Antibiotics were prescribed during admission to 181 (89.6\%) cases, with 142 (70.3\%) received a macrolide. Comparing the frequency of the clinical presentations between PCR-positive pertussis cases with virus coinfection and those

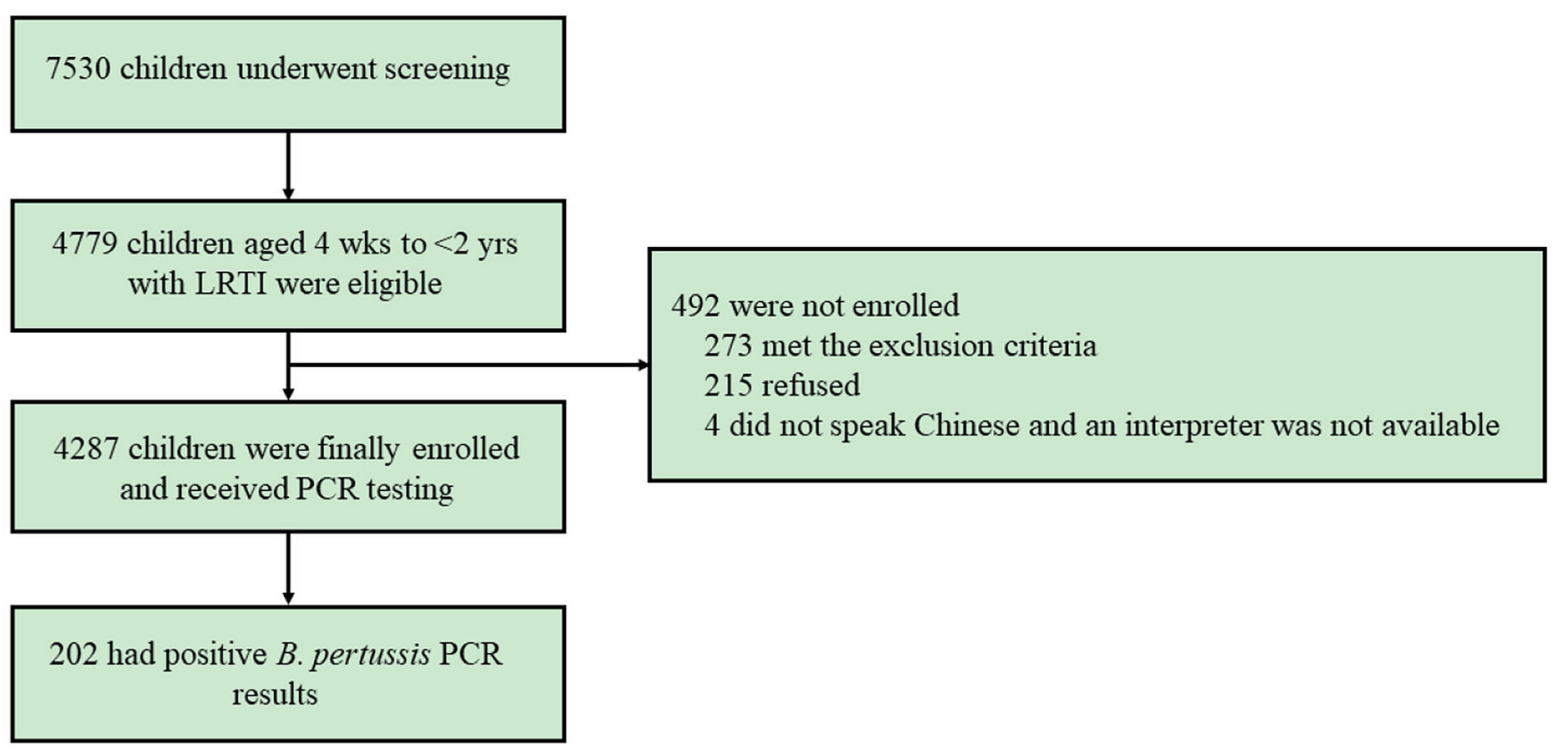

Fig. 2 Study enrollment and final pertussis cases 
Table 1 Demographic characteristics of the children enrolled in the study and children with pertussis infections

\begin{tabular}{lll}
\hline Characteristics & $\begin{array}{l}\text { Children enrolled in the study } \\
(\boldsymbol{n}=\mathbf{4 2 8 7})\end{array}$ & $\begin{array}{l}\text { Children with pertussis infections } \\
(\boldsymbol{n}=\mathbf{2 0 2})\end{array}$ \\
\hline Age at hospitalization, m, median (IQR) & $4(2-9)$ & $3.5(2.0-7.3)$ \\
$<3 \mathrm{~m}$ & $1492(34.8)$ & $67(33.2)$ \\
3 to $<6 \mathrm{~m}$ & $1106(25.8)$ & $73(36.1)$ \\
6 to $<12 \mathrm{~m}$ & $969(22.6)$ & $33(16.3)$ \\
12 to $<24 \mathrm{~m}$ & $716(16.7)$ & $29(14.4)$ \\
Male & $2791(65.1)$ & $109(54.0)$ \\
Immunization status & & $102(50.5)$ \\
Unvaccinated & $1753(40.9)$ & \\
\hline
\end{tabular}

Data are presented as No. (\%) unless otherwise indicated $m$ months

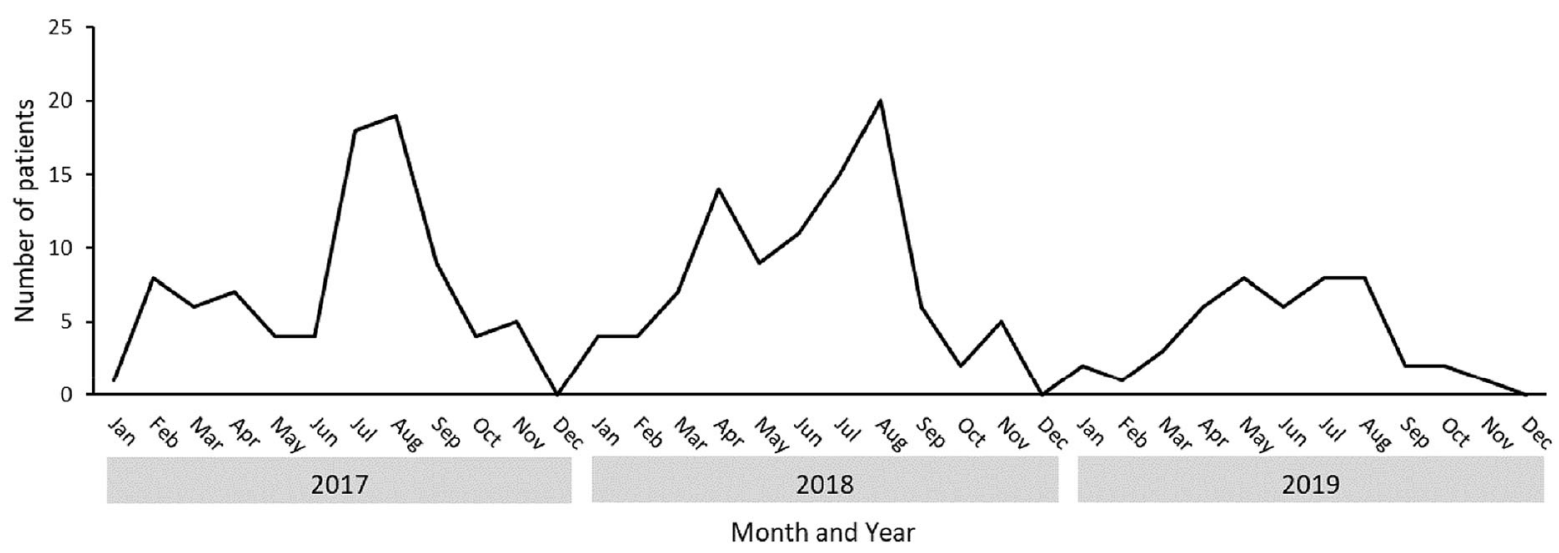

Fig. 3 Seasonal distribution of $B$. pertussis infection

without coinfection, there were no differences (Table 3).

\section{Clinical Outcomes}

Children with virus coinfection were significantly more likely to present with pneumonia than those with a single $B$. pertussis infection [odds ratio (OR) 1.84; 95\% confidence interval (CI) $1.04-3.25 ; \quad P=0.036]$. However, virus coinfection did not affect the clinical severity in those with $B$. pertussis-associated infection (OR 0.75; CI 0.39-1.44; Table 4). Age and vaccination status confounded the association between virus coinfection and the presence of pneumonia and disease severity. Both patients receiving 3 doses and 1-2 doses had decreased odds of presence of pneumonia compared with unvaccinated patients (OR 0.59; CI 0.42-0.83 and OR 0.45; CI 0.22-0.96, respectively). Similarly, patients receiving 3 doses and 1-2 doses had reduced frequencies of severe disease compared with unvaccinated patients (OR 0.52; CI 
Table 2 Association of respiratory viruses and pertussis infections

\begin{tabular}{|c|c|c|c|c|}
\hline Virus & $\begin{array}{l}\text { Pertussis PCR-positive } \\
\text { cases }(n=202)\end{array}$ & $\begin{array}{l}\text { Pertussis PCR-negative } \\
\text { cases }(n=4085)\end{array}$ & OR (95\% CI) & $\begin{array}{l}\text { Age-adjusted OR } \\
(95 \% \mathrm{CI})\end{array}$ \\
\hline $\begin{array}{l}\text { Respiratory } \\
\text { syncytial virus }\end{array}$ & $5(2.5)$ & $751(18.4)$ & $\begin{array}{l}0.12 \\
\quad(0.05-0.30)\end{array}$ & $0.11(0.04-0.27)$ \\
\hline Human rhinovirus & $52(25.7)$ & $337(8.2)$ & $\begin{array}{l}3.71 \\
\quad(2.34-5.89)\end{array}$ & $8.89(4.75-16.64)$ \\
\hline Human bocavirus & $17(8.4)$ & $379(9.3)$ & $\begin{array}{l}0.70 \\
\quad(0.40-1.25)\end{array}$ & - \\
\hline $\begin{array}{l}\text { Human } \\
\text { metapneumovirus }\end{array}$ & $2(1.0)$ & $36(0.9)$ & $\begin{array}{l}1.43 \\
\quad(0.24-8.65)\end{array}$ & - \\
\hline Influenza virus $\mathrm{A} / \mathrm{B}$ & $3(1.5)$ & $44(1.1)$ & $\begin{array}{l}2.16 \\
\quad(0.43-10.8)\end{array}$ & - \\
\hline Adenovirus & 0 & $52(1.3)$ & - & - \\
\hline $\begin{array}{l}\text { Parainfluenza virus } \\
\text { I/II/III }\end{array}$ & $12(5.9)$ & $268(6.6)$ & $\begin{array}{l}0.91 \\
\quad(0.46-1.84)\end{array}$ & - \\
\hline $\begin{array}{l}\text { At least } 1 \\
\text { respiratory virus }\end{array}$ & $81(40.1)$ & $1781(43.6)$ & $\begin{array}{l}0.86 \\
\quad(0.62-1.21)\end{array}$ & - \\
\hline
\end{tabular}

Data are presented as No. (\%) unless otherwise indicated

$C I$ confidence interval, $O R$ odds ratio, $P C R$ polymerase chain reaction

OR $(95 \% \mathrm{CI})$ was presented bold when significance was found between the two groups

0.33-0.81 and OR $0.49 ; \quad$ CI $0.21-0.93$, respectively).

After adjusting for age and vaccination status, children with virus coinfection were 2.62 times more likely to present with pneumonia than those with a single $B$. pertussis infection (Table 4). Stratified analysis of children aged 4 weeks to 3 months and 4 to $<24$ months found a strong association between virus coinfection and the presence of pneumonia among children aged 4 to $<24$ months (OR 5.0; CI 2.05-12.23; Supplementary Tables 1 and 2).

When further analyzed by the coinfected virus (HRV or non-HRV virus), after adjusting for age and vaccination status, both patients with HRV and non-HRV virus coinfection had increased odds of presenting pneumonia compared with those with single $B$. pertussis infection (OR 3.29; CI 1.27-8.52 and OR 2.47; CI 1.18-5.16, respectively; Supplementary Tables 3 and 4).

\section{DISCUSSION}

Three of the important findings reported in our study are as follows: (1) the burden of $B$. pertussis-associated hospitalization in children was high in Suzhou, China; (2) coinfections were common in $B$. pertussis-associated LRTI, with HRV being the most commonly coinfected virus; and (3) no differences in clinical severity were observed between children with virus coinfection compared to those with single $B$. pertussis infection.

Our B. pertussis-associated infection rate $(6.1 \%)$ in LRTIs was higher than those of previous studies $[8,9,17]$ but lower than those reported by other studies $[18,19]$. The discrepancies in the rates of $B$. pertussis-associated infection may result from different health systems in differing regions, differences in age groups, and laboratory assays. A Soweto, South Africa, study enrolled infants $<1$ year of age 
Table 3 Clinical characteristics at admission of the pertussis polymerase chain reaction-positive children with or without virus coinfection

\begin{tabular}{|c|c|c|c|}
\hline Characteristics & $\begin{array}{l}\text { All PCR-positive } \\
\text { pertussis cases } \\
(n=202)\end{array}$ & $\begin{array}{l}\text { PCR-positive pertussis cases } \\
\text { with virus coinfection } \\
(n=81)\end{array}$ & $\begin{array}{l}\text { PCR-positive pertussis cases } \\
\text { without virus coinfection } \\
(n=121)\end{array}$ \\
\hline $\begin{array}{l}\text { Age at admission, } \\
\text { months, median } \\
\text { (IQR) }\end{array}$ & $3.5(2.0-7.3)$ & $4.0(2.0-10.0)$ & $3.0(2.0-5.0)$ \\
\hline Male & $108(53.5)$ & $42(51.9)$ & $66(54.5)$ \\
\hline \multicolumn{4}{|l|}{ Pertussis vaccine doses } \\
\hline 0 & $102(50.5)$ & $41(50.6)$ & $61(50.4)$ \\
\hline 1 & $21(10.4)$ & $6(7.4)$ & $15(12.4)$ \\
\hline 2 & $20(9.9)$ & $3(3.7)$ & $17(14.0)$ \\
\hline 3 & $59(29.2)$ & $31(38.3)$ & $28(23.1)$ \\
\hline \multicolumn{4}{|l|}{ Symptoms and signs } \\
\hline Cough & $202(100)$ & $81(100)$ & $121(100)$ \\
\hline Paroxysmal cough & $190(94.1)$ & $75(92.6)$ & $115(95.0)$ \\
\hline Whoop & $47(23.3)$ & $16(19.8)$ & $31(25.6)$ \\
\hline Cyanosis & $20(9.9)$ & $12(14.8)$ & $8(6.6)$ \\
\hline Posttussive emesis & $81(40.1)$ & $31(38.3)$ & $50(41.3)$ \\
\hline Fever & $30(14.9)$ & $15(18.5)$ & $15(12.4)$ \\
\hline Wheezing & $58(28.7)$ & $28(34.6)$ & $30(24.8)$ \\
\hline $\begin{array}{l}\text { Cough duration before } \\
\text { admission } \geq 14 \text { days }\end{array}$ & $86(42.6)$ & $33(40.7)$ & $53(43.8)$ \\
\hline $\begin{array}{l}\text { Fulfilling CDC criteria } \\
\text { for probable pertussis }\end{array}$ & $146(72.3)$ & $56(69.1)$ & $90(74.4)$ \\
\hline $\begin{array}{l}\text { White blood } \\
\text { cells, } \times 10^{9} / \mathrm{L} \text {, mean } \\
(\mathrm{SD})\end{array}$ & $17.7(8.8)$ & $17.6(9.8)$ & $17.8(8.0)$ \\
\hline $\begin{array}{l}\text { White blood } \\
\text { cells }>20 \times 10^{9} / \mathrm{L}\end{array}$ & $59(29.2)$ & $24(29.6)$ & $35(28.9)$ \\
\hline
\end{tabular}

Data are presented as No. (\%) unless otherwise indicated

$C D C$ Centers for Disease Control and Prevention, $I Q R$ interquartile range, $P C R$ polymerase chain reaction, $S D$ standard deviation

hospitalized with LTRI and identified a rate of $2.3 \%$ [8]. Another study from Cape Town, South Africa, reported a $7 \%$ prevalence for the detection of $B$. pertussis in children $<13$ years hospitalized with LRTI [18]. In China, a recent study from Shenzhen reported a rate of $4.51 \%$ [20] in children $<14$ years [20]. 
Table 4 Associations of virus coinfection with clinical outcomes, multiple logistic regression analysis

\begin{tabular}{|c|c|c|c|c|}
\hline Outcome & $\begin{array}{l}\text { Single pertussis infection } \\
(n=121)\end{array}$ & $\begin{array}{l}\text { Pertussis-virus coinfection } \\
(n=81)\end{array}$ & OR (95\% CI) & $\begin{array}{l}\text { Adjusted OR }(95 \% \\
\text { CI })^{\mathrm{a}}\end{array}$ \\
\hline \multicolumn{5}{|c|}{ Positive radiograph for pneumonia } \\
\hline Yes & $49(40.5)$ & $45(55.6)$ & $\begin{array}{l}1.84 \\
\quad(1.04-3.25)\end{array}$ & $2.62(1.39-4.91)$ \\
\hline No & $72(59.5)$ & $36(44.4)$ & Referent & - \\
\hline \multicolumn{5}{|c|}{ Severe illness } \\
\hline Yes & $35(28.9)$ & $18(22.2)$ & $\begin{array}{l}0.75 \\
\quad(0.39-1.44)\end{array}$ & $0.94(0.48-1.86)$ \\
\hline No & $86(71.1)$ & $63(77.8)$ & Referent & - \\
\hline
\end{tabular}

$C I$ confidence interval, $O R$ odds ratio

${ }^{\text {a }}$ Multivariable analysis adjusted for age and the vaccination status

OR (95\% CI) was presented bold when significance was found between the two groups

In the present study, $29.2 \%$ of all PCR-positive pertussis cases were identified in children who received 3 doses of vaccine. Marshall et al. also reported that $18.8 \%$ of the PCR-positive pertussis cases had received more than 2 doses of vaccine [21]. In 2014, Zhang et al. conducted a Cochrane review of efficacy of one-, two-, and multicomponent vaccines in children. They found that the efficacies of multicomponent vaccines in preventing severe and mild pertussis were $84 \sim 85 \%$ and $71 \sim 78 \%$, respectively [22]. Lower immunization rates among adolescents and adults and evolution of $B$. pertussis have been attributed to the high incidence rates of pertussis despite the children being fully vaccinated [5].

In our study, HRV was the most commonly coinfected virus among children with $B$. pertussis-associated LRTI, which is in line with previous studies [10, 21, 23]. Other studies have found that RSV was the most commonly coinfected virus $[11,24,25]$. The heterogeneity of social demography, differences in study methodology, and the year of study may influence the documented coinfected viruses. The high prevalence of HRV in $B$. pertussis LRTI highlights its important role in pertussis in our region. Our recent study also reported that HRV was the most common virus presenting with a pertussis-like syndrome [26]. Previous studies have found that patients shed HRV for weeks after infection, and could be detected in symptomatic and asymptomatic children [27]. However, in our study, the prevalence of HRV was significantly higher among the B. pertussis PCRpositive children than that among the PCRnegative children $(25.7 \%$ vs. $8.2 \%, P<0.01)$. We believe that this result demonstrates the real high HRV coinfection burn in $B$. pertussis LRTI.

We have reported that virus coinfection was associated with developing pneumonia but not with severe illness. To our knowledge, studies focusing on the clinical outcome of virus coinfection in pertussis have resulted in divergent findings. Marshall et al. designed a pertussis severity score system, and found that the presence of coinfection was independently associated with severe disease [21]. Kaczmarek et al. investigated pertussis-related pediatric intensive care unit (ICU) admissions, and reported that patients with coinfection had a longer length of ICU stay [24]. A recent study in China found that children with virus coinfection did not experience a more severe disease than those with a single pertussis infection [25]. Variation in age group selection, definition of severity, and adjustment in multivariable analyses may affect the findings.

To investigate whether there were patients who presented with atypical pertussis-like symptoms, we used broad inclusion for investigating $B$. pertussis-associated LRTI. Our study 
found that $72.3 \%$ of the pertussis PCR-positive patients fulfilled the CDC case definition of pertussis. Soofie et al. reported that only $38 \%$ of pertussis PCR-positive cases fulfilled the CDC case definition [8]. Alaso, Phadke et al. reported that only $27.3 \%$ met the CDC case definition [9]. This calls to attention that different definitions might be used to determine the true epidemiologic burden of pertussis. The wide use of PCR assays as a diagnostic method for the detection of pertussis might help to provide a new definition for this disease.

An important strength of our study was the use of extensive comparison groups (single vs. coinfection HRV/non-HRV virus, 4 weeks-3 months vs. 4 to $<24$ months), each with adequate sample sizes, although our sample size did not allow subgroup analyses for all individual viruses or for more age subgroups to be included. Our study also has some limitations. First, we only assessed the presence or absence of coinfected viruses; we did not measure the virus load, which might have better elucidated the association between the virus and disease severity. Second, as is also the case for other studies, this study was performed at a single tertiary referral hospital and the outpatients with mild LRTI were not included in our study, which limits the generalizability of our findings. Third, we only included patients older than 4 weeks; we did not include neonates, which is unfortunate as many of the severe cases of pertussis occur in them.

We used a two-target assay (ptxS1 and IS481) that allowed identification of $B$. pertussis, although a false diagnosis of pertussis could be made because IS481 is also found in $B$. holmesii [15]. However, previous studies have found that $B$. holmesii infections are rare and mostly occur in older children and adults. Valero-Rello et al. reported that $B$. holmesii was detected in only $0.9 \%$ (only in patients $>4$ years old) of patients suspected of pertussis [28]. Burgos-Rivera also reported a low positive rate of $0.66 \%$ [29]. Fraj et al. investigated 1844 children with respiratory infections and found that none had $B$. holmesii infection [30]. A study from Spain reevaluated 391 B. pertussis-positive (IS481-based) samples by using multiplex RT-PCR. They found that $B$. holmesii was positive in only $4.1 \%$ of the patients with a median age of 9 years old [31]. As we only included children $<2$ years old and performed PCR testing on a large number of patients $(n=4287)$, we determined that the two-target assay was acceptable and profitable for evaluating the burden of $B$. pertussis in our region, although most of the Chinese clinical laboratories have limited multitarget PCR capacity.

\section{CONCLUSION}

In conclusion, $B$. pertussis infection contributed to a high proportion of LRTI hospitalizations among southeast Chinese children. Equivalent clinical severity was observed between children with virus coinfection and single $B$. pertussis infection, although children coinfected with virus presented more frequently with pneumonia than those with single $B$. pertussis infection.

\section{ACKNOWLEDGEMENTS}

We thank the participants of the study. We would like to thank the Elsevier Language Editing Services for their English language editing.

Funding. This work was supported by a grant from the National Natural Science Foundation of China (Grant No. 81573167), Social Development, Science and Technology Projects of Jiangsu Province (Grant BE2019671). The Rapid Service Fees were funded by the authors.

Authorship. All named authors meet the International Committee of Medical Journal Editors (ICMJE) criteria for authorship for this article, take responsibility for the integrity of the work as a whole, and have given their approval for this version to be published.

Authorship Contributions. YW and $\mathrm{CH}$ conceived and designed the study; SC, KW and AL collected data; MW and ZC analyzed the data and interpreted the results; JX and XS performed the microbiology; WJ wrote the first draft; all authors critically revised the paper and 
gave final approval for publication. WJ, MW and SC contributed equally to this work.

Disclosures. Wujun Jiang, Min Wu, Sainan Chen, Anrong Li, Kun Wang, Yuqing Wang, Zhengrong Chen, Chuangli Hao, Xuejun Shao and Jun $\mathrm{Xu}$ have nothing to disclose.

Compliance with Ethics Guidelines. The study protocol was approved by the Ethics Committee of Children's Hospital of Soochow University (No: 2016026) and was conducted in accordance with Good Clinical Practice guidelines and the Helsinki Declaration. Legal guardians of the study participants were counselled on the study and study-related procedures prior to obtaining a signed informed consent.

Data Availability. The datasets generated during and/or analyzed during the current study are not publicly available due to the privacy of participants.

Open Access. This article is licensed under a Creative Commons Attribution-NonCommercial 4.0 International License, which permits any non-commercial use, sharing, adaptation, distribution and reproduction in any medium or format, as long as you give appropriate credit to the original author(s) and the source, provide a link to the Creative Commons licence, and indicate if changes were made. The images or other third party material in this article are included in the article's Creative Commons licence, unless indicated otherwise in a credit line to the material. If material is not included in the article's Creative Commons licence and your intended use is not permitted by statutory regulation or exceeds the permitted use, you will need to obtain permission directly from the copyright holder. To view a copy of this licence, visit http://creativecommons.org/licenses/by$\mathrm{nc} / 4.0 /$.

\section{REFERENCES}

1. Cherry JD. Epidemic pertussis in 2012-the resurgence of a vaccine-preventable disease. N Engl J Med. 2012;367:785-7.
2. Liu L, Oza S, Hogan D, et al. Global, regional, and national causes of under-5 mortality in 2000-15: an updated systematic analysis with implications for the Sustainable Development Goals. Lancet. 2016;388:3027-35.

3. Yeung KHT, Dluclos P, Nelson EAS, et al. An update of the global burden of pertussis in children younger than 5 years: a modelling study. Lancet Infect Dis. 2017;17:974-80.

4. Xu Y, Wang L, Xu J, et al. Seroprevalence of pertussis in China: need to improve vaccination strategies. Hum Vaccin Immunother. 2014;10: 192-8.

5. Kilgore PE, Salim AM, Zervos MJ, et al. Pertussis: microbiology, disease, treatment, and prevention. Clin Microbiol Rev. 2016;29:449-86.

6. Nieves DJ, Singh J, Ashouri N, et al. Clinical and laboratory features of pertussis in infants at the onset of a California epidemic. J Pediatr. 2011;159: 1044-6.

7. Berger JT, Carcillo JA, Shanley TP, et al. Critical pertussis illness in children: a multicenter prospective cohort study. Pediatr Crit Care Med. 2013;14: 356-65.

8. Soofie N, Nunes MC, Kgagudi P, et al. The burden of pertussis hospitalization in HIV-exposed and HIVunexposed South African infants. Clin Infect Dis. 2016;63:S165-73.

9. Phadke VK, McCracken JP, Kriss JL, et al. Clinical characteristics of hospitalized infants with laboratory-confirmed pertussis in guatemala. J Pediatr Infect Dis Soc. 2018;7:310-6.

10. Frassanito A, Nenna R, Nicolai A, et al. Infants hospitalized for Bordetella pertussis infection commonly have respiratory viral coinfections. BMC Infect Dis. 2017;17:492.

11. Huang H, Deng L, Xiao F, et al. Clinical analysis of children with pertussis and significance of respiratory virus detection in the combined diagnosis. Zhonghua Er Ke Za Zhi. 2017;55:580-5.

12. Jiang W, Mao L, Wang $\mathrm{K}$, et al. Prevalence of $B$. pertussis infection in children with clinically suspected pertussis. J Microbiol Immunol Infect. 2020. https://doi.org/10.1016/j.jmii.2020.03.006.

13. Fancourt N, Deloria Knoll M, Barger-Kamate B, et al. Standardized interpretation of chest radiographs in cases of pediatric pneumonia from the PERCH study. Clin Infect Dis. 2017;64:S253-61.

14. Barlow RS, Reynolds LE, Cieslak PR, et al. Vaccinated children and adolescents with pertussis 
infections experience reduced illness severity and duration, Oregon, 2010-2012. Clin Infect Dis. 2014;58:1523-9.

15. Tatti KM, Sparks KN, Boney KO, et al. Novel multitarget real-time PCR assay for rapid detection of Bordetella species in clinical specimens. J Clin Microbiol. 2011;49:4059-66.

16. Jain S, Williams DJ, Arnold SR, et al. Community-acquired pneumonia requiring hospitalization among U.S. children. N Engl J Med. 2015;372:835-45.

17. Jusot V, Aberrane S, Ale F, et al. Prevalence of Bordetella infection in a hospital setting in niamey, niger. J Trop Pediatr. 2014;60:223-30.

18. Muloiwa R, Dube FS, Nicol MP, et al. Incidence and diagnosis of Pertussis in South African children hospitalized with lower respiratory tract infection. Pediatr Infect Dis J. 2016;35:611-6.

19. Zouari A, Smaoui H, Brun D, et al. Prevalence of Bordetella pertussis and Bordetella parapertussis infections in Tunisian hospitalized infants: results of a 4-year prospective study. Diagn Microbiol Infect Dis. 2012;72:303-17.

20. Wang H, Zheng Y, de Groot R, et al. High prevalence of Bordetella pertussis in young hospitalized infants with acute respiratory infection in the south of China: age- and season-dependent effects. J Infect. 2020;80:578-606.

21. Marshall H, Clarke M, Rasiah K, et al. Predictors of disease severity in children hospitalized for pertussis during an epidemic. Pediatr Infect Dis J. 2015;34: 339-45.

22. Zhang L, Prietsch SO, Axelsson I, et al. Acellular vaccines for preventing whooping cough in children. Cochrane Database Syst Rev. 2014;2014: CD001478.

23. Yang S, Li H, Tang Y, et al. Multiplex tests for respiratory tract infections: the direct utility of the
FilmArray respiratory panel in emergency department. Can Respir J. 2020;2020:6014563.

24. Kaczmarek MC, Ware RS, McEniery JA, et al. Epidemiology of pertussis-related paediatric intensive care unit (ICU) admissions in Australia, 1997-2013: an observational study. BMJ Open. 2016;6:e010386.

25. Tao Y, Tang M, Luo L, et al. Identification of etiologic agents and clinical characteristics for patients suspected of having pertussis in a large Children's Hospital in China. Ann Transl Med. 2019;7:443.

26. Gu W, Wang K, Zhang X, et al. Pathogen analysis of pertussis-like syndrome in children. BMC Infect Dis. 2020;20:353.

27. Howard LM, Johnson M, Williams JV, et al. Respiratory viral detections during symptomatic and asymptomatic periods in young andean children. Pediatr Infect Dis J. 2015;34:1074-80.

28. Valero-Rello A, Henares D, Acosta L, et al. Validation and implementation of a diagnostic algorithm for DNA detection of Bordetella pertussis, B. parapertussis, and $B$. holmesii in a pediatric referral hospital in Barcelona, Spain. J Clin Microbiol. 2019;57.

29. Burgos-Rivera B, Lee AD, Bowden KE, et al. Evaluation of level of agreement in bordetella species identification in three US laboratories during a period of increased pertussis. J Clin Microbiol. 2015;53:1842-7.

30. Ben Fraj I, Kechrid A, Guillot S, et al. Pertussis epidemiology in Tunisian infants and children and characterization of Bordetella pertussis isolates: results of a 9-year surveillance study, 2007 to 2016. J Med Microbiol. 2019;68:241-7.

31. Mir-Cros A, Codina G, Martin-Gomez MT, et al. Emergence of Bordetella holmesii as a causative agent of whooping cough, Barcelona, Spain. Emerg Infect Dis. 2017;23:1856-9. 